\title{
Коррекция характеристик кремниевых фотодиодов путем применения ионной имплантации
}

\author{
(C) В.Е. Асадчиков ${ }^{1}$, И.Г. Дьячкова ${ }^{1, \uparrow}$, Д.А. Золотов ${ }^{1}$, Ф.Н. Чуховский ${ }^{1}$, Е.В. Никитина ${ }^{2}$ \\ ${ }^{1}$ Федеральный научно-исследовательский центр „Кристаллография и фротоника“ \\ Российской академии наук, \\ 119333 Москва, Россия \\ ${ }^{2}$ Санкт-Петербургский национальный исследовательский Академический университет им. Ж.И. Алферова \\ Российской академии наук, \\ 194021 Санкт-Петербург, Россия \\ ฯ E-mail: sig74@mail.ru
}

Поступила в Редакцию 16 января 2020 г.

В окончательной редакции 27 января 2020 г.

Принята к публикации 27 января 2020 г.

\begin{abstract}
Рассмотрены результаты измерений электрофизических параметров кремниевых pin-фотодиодов после имплантации дефектообразующих ионов и последующей термической обработки, которые открывают новый способ уменьшения темнового тока и увеличения выхода годных приборов. Данные электрофизических измерений сопоставлены с результатами структурных исследований. Экспериментально установлена эффективность облучения протонами периферии $n^{+}-p$-переходов для защиты поверхности рin-фотодиодов на основе высокоомного кремния. Определены оптимальные условия - режимы облучения протонами и последующего термического отжига (энергии $E=100+200+300$ кэВ, доза $D=2 \cdot 10^{16} \mathrm{~cm}^{-2}$, температура $T=300^{\circ} \mathrm{C}$, время $t=2$ ч), при которых происходит формирование поверхностного слоя с оптимальными для достижения минимальных темновых токов фоточувствительных площадок и охранного кольца характеристиками. Применение этих режимов к серийным pin-фотодиодам с глубиной залегания $n^{+}-p$-переходов $\sim 3$ мкм позволило снизить темновой ток на порядок величины и повысить выход годных приборов.
\end{abstract}

Ключевые слова: фотодиоды, имплантация протонов, термический отжиг, радиационные дефекты, темновой ток.

DOI: $10.21883 /$ FTP.2020.06.49385.9347

\section{1. Введение}

В современной кремниевой микроэлектронике для создания слоев с заданными электрофизическими свойствами широко применяется ионная имплантация [1,2]. В последние годы в связи с развитием технологии „кремний-на-изоляторе“ (КНИ) для создания полупроводниковых приборов особую актуальность приобрели вопросы, связанные с имплантацией ионов водорода в кристаллический кремний [3-6].

Одной из главных задач при производстве кремниевых импульсных pin-фотодиодов ( pin-ФД) является достижение максимальной величины пороговой чувствительности $[7,8]$. Для фотодиодов одним из отбраковочных параметров является темновой ток фоточувствительных площадок (ФЧП) при рабочем напряжении [9]. Уменьшение темновых токов за счет сложной многоступенчатой обработки поверхности кремния и прецизионных режимов окисления, обеспечивающих оптимальное поверхностное сопротивление $\left(R_{S}\right)$, резко повышает себестоимость приборов. Традиционно применяемый для снижения темновых токов ФЧП топологический прием - создание охранного кольца (ОК) [10-12], которое представляет собой дополнительный обратносмещенный $p-n$-переход, расположенный вокруг ФЧП, - часто не позволяет разрешить проблему уменьшения темновых токов.
В работе ставилась задача оптимизировать поверхностное сопротивление, обеспечивающее оптимальное перетекание тока из площадок в ОК и, следовательно, минимальные темновые токи ФЧП, без предъявления высоких требований к чистоте обработки поверхности и режимам окисления кремния. Для решения этой задачи нами использовалась ионная имплантация. Имплантация легких глубоко проникающих ионов (например, ионов водорода) позволяет формировать глубокие однородные дефектные слои в кристалле при наличии поверхностной защитной пленки, а изменяя энергию облучения, можно управлять глубиной проникновения ионов в кремний. При введении компенсирующих дефектов в приповерхностную область периферии планарных $p-n$-переходов путем имплантации ионов водорода можно добиться снижения уровня поверхностных токов утечки в полностью изготовленных приборных структурах, ранее не соответствующих требованию по уровню темнового тока.

В настоящей работе проведены исследования методами трехкристальной рентгеновской дифрактометрии (ТРД) и просвечивающей электронной микроскопии (ПЭМ) состояния нарушенного слоя в кристаллическом кремнии, сформированного путем имплантации ионов водорода с последующей термической обработкой. С помощью этих двух методов ставилась задача исследовать основные структурные изменения, протекающие 
при имплантации протонов в кремний и последующей термической обработке, с целью анализа потенциальных возможностей практического применения получаемых модифицированных слоев с особыми электрофизическими свойствами.

\section{2. Описание образцов, обоснование выбора режимов имплантации и последующей термической обработки}

Конкретным объектом исследования являлись четырехплощадочные pin-фотодиоды, сформированные на пластине высокоомного кремния $p$-типа проводимости, где в результате диффузии примесей были образованы области ФЧП и ОК. Был поставлен комплексный эксперимент по изучению влияния протонного облучения и температуры последующего отжига на темновой ток ФЧП и ОК диффузионных планарных кремниевых pin-ФД при облучении периферии $p-n$-переходов, а также на профиль удельного сопротивления и структурное состояние ионно-имплантированного слоя в образцах $p$-Si (удельное сопротивление $\sim 1$ кОм·см) с ориентацией поверхности (111). Режим облучения выбран следующий: последовательное ступенчатое увеличение энергии протонов. При этом энергии облучения составляли 100 , 200 и 300 кэВ (далее по тексту $E=100+200+300$ кэВ) с общей дозой $D=2 \cdot 10^{16} \mathrm{~cm}^{-2}$. Облучение образцов проводилось на ускорителе КГ-500 НИИЯФ МГУ. Последующая термообработка проводилась в вакууме при температурах от 200 до $1100^{\circ} \mathrm{C}$ через $100^{\circ} \mathrm{C}$ в течение 2 ч при каждой температуре.

Выбор дозы связан с необходимостью получения слоя с максимальным количеством нарушений. Предварительные измерения зависимостей профиля удельного сопротивления кремния и поверхностного сопротивления от дозы облучения протонами показали, что пороговое значение дозы $D=2 \cdot 10^{16} \mathrm{~cm}^{-2}$ соответствует достижению наибольшего сопротивления облученного слоя. Увеличение дозы облучения кремния протонами выше величины $2 \cdot 10^{16} \mathrm{~cm}^{-2}$, как показано в [13], приводит к образованию газовых пузырей и разрушению кристаллов кремния при последующей термообработке. Выбор энергий имплантированных протонов обусловлен желанием создать нарушенный слой на глубинах, соизмеримых с глубиной залегания $p-n$-перехода в реальных заводских структурах (от 2 до 3 мкм). В работе были рассчитаны профили распределения внедренных ионов водорода в кремний методом Пирсона [14]. Величина проективного пробега составила $\sim 1$ мкм для протонов с энергией 100 кэВ, $\sim 1.9$ мкм для 200 кэВ, $\sim 3$ мкм для 300 кэВ. Кроме того, предварительные измерения зависимостей профиля удельного сопротивления кремния от энергии протонов показали, что облучение с последовательно увеличивающейся энергией протонов от 100 до 300 кэВ позволяет сформировать однородный по величине удельного сопротивления дефектный слой на глубинах, соответствующих глубине залегания $p-n$-перехода.

Длительность отжига обусловлена необходимостью стабилизации свойств заглубленного слоя с повышенным удельным сопротивлением, изолирующего слой с оптимальным сопротивлением от объема кристалла. Отклонение от временны́х параметров отжига значительно снижает эффективность указанной обработки.

Изучение процессов формирования и релаксации радиационных дефектов, возникающих при имплантации кремния ионами водорода, осуществлялось методами трехкристальной рентгеновской дифрактометрии и просвечивающей электронной микроскопии в сочетании с измерениями электрофизических параметров.

\section{3. Результаты и их обсуждение}

Рентгенодифракционные измерения проводились с помощью трехкристального рентгеновского спектрометра ТРС УАР ПП-80-001 с использованием характеристического излучения $\mathrm{CuK}_{\alpha 1}$, с длиной волны $\lambda=1.54051 \AA$ при различных поворотах образца относительно максимума брэгговского отражения. Для образцов, подвергнутых ионной имплантации, помимо главного пика и псевдопика в широком интервале углов наблюдалось интенсивное диффузное рассеяние [15], характер которого менялся в зависимости от режима термической обработки. В работе была исследована зависимость интенсивности главного пика от угла поворота образца [15]. По периоду наблюдаемых периодических изменений интенсивности были определены толщины слоев с положительной и отрицательной деформацией. Для образца, подвергнутого последовательной имплантации протонами с энергией $E=100+200+300$ кэВ, толщина слоя с положительным значением деформации составила 2.4 мкм, с отрицательным - 1 мкм. Эти значения хорошо коррелирует с расчетными оценками, свидетельствуя о том, что такая многоступенчатая имплантация позволяет формировать толстые нарушенные слои с достаточно однородным распределением деформации. Кроме того было изучено распределение интенсивности диффузного рассеяния вдоль направления $q_{z} \|\{111\}$ и $q_{x} \|\{121\}$ в окрестности узла [333] для облученного кристалла $\mathrm{Si}$ при разных режимах термической обработки, на основании которого проводился качественный анализ изменения геометрии присутствующих в образцах кластеров радиационных дефектов, а также определялись количественные характеристики микродефектов, такие как мощность, размер и концентрация [16].

Параллельно более детальное исследование радиационных микродефектов в имплантированных слоях кристаллов кремния проводилось с использованием метода ПЭМ на электронном микроскопе JEM-7 (Физикотехнический институт им. А.Ф. Иоффе) [16]. Результаты исследований представлены в таблице. 
Качественные и количественные оценки характеристик радиационных дефектов в кристалле кремния, подвергнутом имплантации протонов с энергией $E=100+200+300$ кэВ, дозой $D=2 \cdot 10^{16} \mathrm{~cm}^{-2}$ без термообработки и с последующей термообработкой в интервале температур $T=200-1100^{\circ} \mathrm{C}$ по данным методов ТРД и ПЭМ

\begin{tabular}{l|l}
\hline \multicolumn{1}{c|}{ ТРД } & \multicolumn{1}{c}{ ПЭМ } \\
\hline \multicolumn{2}{|c|}{ Без отжига } \\
\hline Присутствуют мелкие микродефекты высокой симметрии. Пре- & Присутствуют типичные радиационные дефекты как результат \\
имущественный тип дефектов - вакансионный с, вероят- & коагуляции точечных радиационных дефектов с образовани- \\
но, сферической симметрией поля смещения, с образованием & ем водородных комплексов размером до 10 нм; очень мел- \\
ассоциаций в виде мелких пор и дислокационных петель. & кие поры слабого контраста размером $\sim 10$ нм, концентрация \\
Мощность для дефектов вакансионного типа составила вели- & $\sim 10^{15}$ см $^{-3}$, а также очень мелкие дислокационные петли, \\
чину $\sim 9 \cdot 10^{-5}$ мкм $^{3}$. & размером $\sim 5$ нм, концентрация $\sim 2 \cdot 10^{12}$ см $^{-3}$. \\
\hline
\end{tabular}

Отжиг при $T=200^{\circ} \mathrm{C}$

Возросла концентрация сравнительно крупных дефектов несферической формы мощностью $\sim 4 \cdot 10^{-4}$ мкм $^{3}$, а так- ные комплексы из них, а не дислокации. же уменьшилась концентрация мелких дефектов, мощностью $\sim 7 \cdot 10^{-5}$ мкм $^{3}$. Увеличилась мощность дефектов вакансионного типа с эффективным радиусом $\sim 0.1$ мкм до значения $\sim 1.4 \cdot 10^{-4}$ мкм $^{3}$.

\section{Отжиг при $T=300^{\circ} \mathrm{C}$}

Уменьшилась концентрация относительно крупных низкосимметричных дефектов. Присутствуют два вида дефектов с разными размерами: крупные, со средним размером $\sim 0.3$ мкм, мощностью $\sim 6 \cdot 10^{-4}$ мкм $^{3}$, и мелкие, со средним размером $\sim 0.05$ мкм, мощностью $\sim 5 \cdot 10^{-5}$ мкм $^{3}$. Преобладают микродефекты вакансионного типа высокой симметрии, концентрация которых практически не изменилась, однако произошло увеличение их среднего размера до величины $\sim 0.2$ мкм и мощности до $\sim 2.4 \cdot 10^{-4}$ мкм $^{3}$. Возросла концентрация микродефектов межузельного типа со сферической симметрией поля смещения, имеющих гладкое распределение по размерам.
Присутствуют круглые (овального вида) дефекты, скорее всего крупные поры (пузыри), со средним размером $\sim(75-150)$ нм, концентрация $\sim 2 \cdot 10^{12} \mathrm{~cm}^{-3}$; очень мелкие дефекты, повидимому, водородные пузырьки, концентрация до $10^{13} \mathrm{~cm}^{-3}$; пластинчатые дефекты, напоминающие дислокационные петли с симметричным дугообразным контрастом (возможно, от одноатомной толщины пластинок, образованных атомами водорода), со средним размером $\sim(50-75)$ нм, концентрация $\sim 3.5 \cdot 10^{12} \mathrm{~cm}^{-3}$.

Отжиг при $T=400^{\circ} \mathrm{C}$

Уменьшилась концентрация относительно крупных низкосимметричных дефектов, а также увеличилась концентрация сравнительно мелких дефектов. При этом концентрация микродефектов вакансионного типа со сферической симметрией поля смещений не изменилась, а концентрация дефектов внедренного типа увеличилась. Присутствуют микродефекты с разными размерами: достаточно крупные, со средним размером $\sim 0.7$ мкм, мощностью $\sim 9 \cdot 10^{-4}$ мкм $^{3}$, и мелкие, со средним размером $\sim 0.08$ мкм, мощностью $\sim 1.2 \cdot 10^{-5}$ мкм $^{3}$.

\section{Отжиг при $T=500^{\circ} \mathrm{C}$}

Возросла концентрация микродефектов как с несферическим, так и со сферическим симметричным полем смещения с преобладанием дефектов вакансионного типа. Присутствуют крупные дефекты, мощностью $\sim 15 \cdot 10^{-4}$ мкм $^{3}$, и относительно мелкие микродефекты, мощностью $\sim 1.4 \cdot 10^{-4}$ мкм $^{3}$.
Присутствуют мелкие дефекты, идентифицированные как полные дислокационные петли межузельного типа с вектором Бюргерса $b=(1 / 2)\langle 110\rangle$, расположенные в наклонных и перпендикулярных к поверхности плоскостях $\{110\}$, со средним радиусом 0.1 мкм; крупные дефекты. идентифицированные как поры (пузыри), со средним размером $\sim 1.2$ мкм, и мелкие поры, со средним размером 50-75 нм, концентрация $\sim 10^{13} \mathrm{~cm}^{-3}$. Размер мелких пор вырос почти в 7 раз, а концентрация снизилась на два порядка по сравнению с облученным образцом без отжига, что связано, по-видимому, с процессом объединения и коагуляции пор с повышением температуры отжига. 
Продолжение таблицы

\begin{tabular}{cc|c}
\hline ТРД & ПЭМ \\
\hline \multicolumn{2}{c}{ Отжиг при $T=600^{\circ} \mathrm{C}$} \\
\hline
\end{tabular}

Присутствуют низкосимметричные микродефекты разных размеров, концентрация которых возросла. При этом концентрация дефектов вакансионного типа со сферической симметрией поля смещения уменьшилась, концентрация микродефектов межузельного типа практически не изменилась. В целом нарушенный слой представляет собой разупорядоченную, насыщенную мелкими вакансионными порами и дислокационными петлями область.

Отжиг при $T=1100^{\circ} \mathrm{C}$

Нарушенный слой представляет собой сильно разупорядоченную структуру, включающую в себя кластеры вакансионного типа низкой симметрии, ассоциированные междоузлия, мощностью $\sim 6.4 \cdot 10^{-4}$ мкм $^{3}$.

Из представленных в таблице результатов видно, что ионно-имплантированный слой кристалла кремния при температурах отжига, превышающих $500^{\circ} \mathrm{C}$, имеет в целом сильно разупорядоченную структуру, насыщенную крупными кластерами радиационных дефектов и дислокациями. Такое состояние ионно-имплантированного слоя не позволяет использовать его в технологии создания и коррекции характеристик pin-фотодиодов. Поэтому при дальнейших исследованиях электрофизических параметров режимы отжига pin-фотодиодов выбраны в интервале температур от 200 до $500^{\circ} \mathrm{C}$.

В работе были проведены исследования влияния протонного облучения и температуры последующего отжига на темновой ток $\left(I_{d}\right)$ ФЧП и ОК, а также на вольтамперные характеристики (BAX) pin-ФД. Кроме того исследованы профили распределения удельного сопротивления кристаллического кремния после облучения и отжига при различных температурах.

Значения темнового тока ФЧП и ОК при обратном смещении $U_{\mathrm{rev}}=200$ В до и после облучения, а также его зависимость от температуры последующего отжига для указанного режима облучения представлены на рис. 1.

Данные, представленные на рис. 1, свидетельствуют о том, что облучение резко, почти на порядок величины, снижает темновой ток и ФЧП, и ОК. Для результатов отжига характерно наличие двух участков температур: $T<300^{\circ} \mathrm{C}$ и $T>300^{\circ} \mathrm{C}$. На первом участке изменение темнового тока при повышении температуры
Нарушенный слой представляет собой сильно разупорядоченную структуру, включающую: дефекты межузельного типа, образующие дислокационные петли с радиусом $\sim 0.4$ мкм и вектором Бюргерса $b=(1 / 2)\langle 110\rangle$, блистеры правильной формы (треугольники, шестиугольники) со средним размером $\sim(1-2)$ мкм, от которых выдавливаются крупные дислокационные петли, расположенные в наклонных и перпендикулярных поверхности плоскостях $\{110\}-$ полные дислокации с вектором Бюргерса $b=(1 / 2)\langle 110\rangle$ межузельной природы, мелкопористые области со средним размером пор $\sim 30$ нм, мелкие дислокационные петли с линией нулевого контраста, параллельной направлениям типа $\langle 110\rangle$, большой концентрации.

незначительно, но противоположно для ФЧП и ОК. Ток ФЧП плавно уменьшается (рис. 1, $a$ ), а ток ОК плавно увеличивается (рис. $1, b)$, причем при $T>200^{\circ} \mathrm{C}$ крутизна роста тока ОК заметно повышается. На втором участке токи как ФЧП, так и ОК возрастают и достигают исходных значений при $T=500^{\circ} \mathrm{C}$. Исходя из этих данных, мы исследовали профили распределения удельного сопротивления кристаллического кремния после облучения и последующего отжига при температурах 200 и $300^{\circ} \mathrm{C}$ (рис. 2).

Как видно из данных рис. 2, облучение приводит к образованию поверхностного слоя с удельным сопротивлением, повышенным в 6 раз сопротивление исходного кристалла (рис. 2, кривая 1). Протяженность этого слоя составляет 2-4 мкм. Рассчитанный нами пробег протонов в кремнии составил 3 мкм. Таким образом, полученные значения находятся в хорошем соответствии. Сопоставив данные электрофизических измерений с данными исследований методами ТРД и ПЭМ, приведенными в таблице, можно заключить, что облучение кремния протонами приводит к накоплению радиационных дефектов, обладающих способностью компенсировать проводимость, только в области сильных нарушений, каковой и является область пробегов протонов [17].

Обратим внимание, что в результате отжига при температурах 200 (рис. 2, кривая 2) и $300^{\circ} \mathrm{C}$ (рис. 2, кривая 3) наблюдается падение удельного сопротивления поверхностного слоя. В то же время при температуре отжига $300^{\circ} \mathrm{C}$ удельное сопротивление этого слоя 

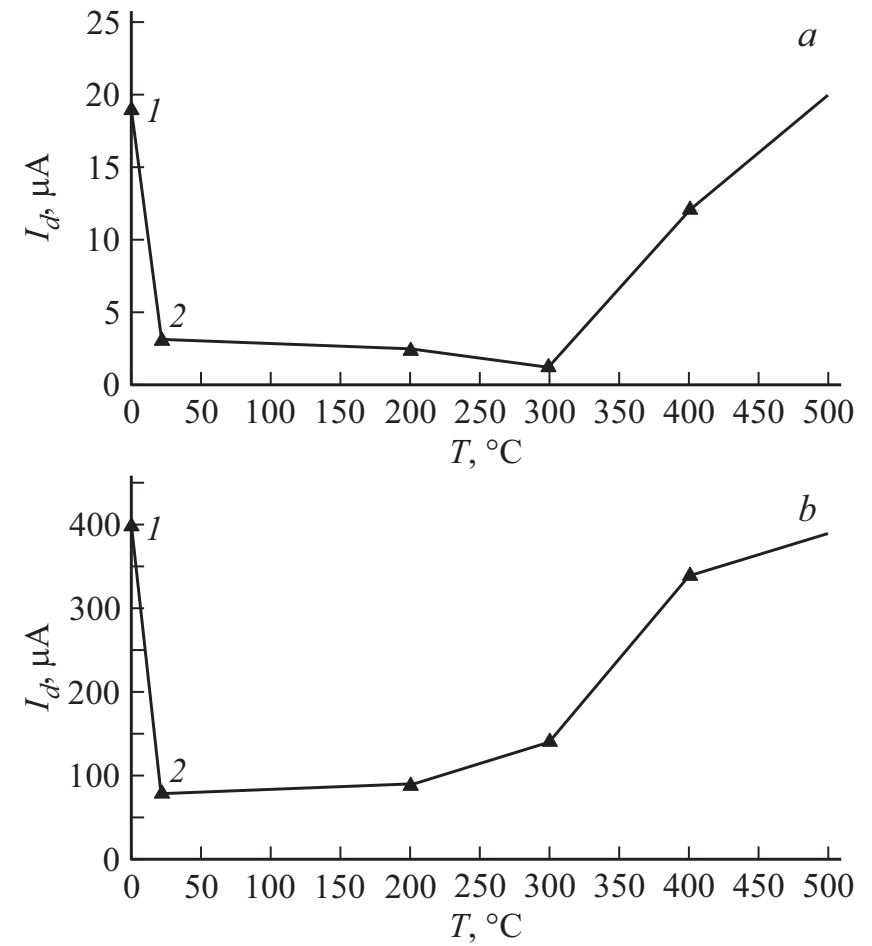

Рис. 1. Значения темнового тока ФЧП $(a)$ и ОК $(b)$ до облучения (1), после облучения (2) протонами (энергия $E=100+200+300$ кэВ, доза $\left.D=2 \cdot 10^{16} \mathrm{~cm}^{-2}\right)$ и зависимости темнового тока ФЧП $(a)$, ОК $(b)$ от температуры последующего отжига.

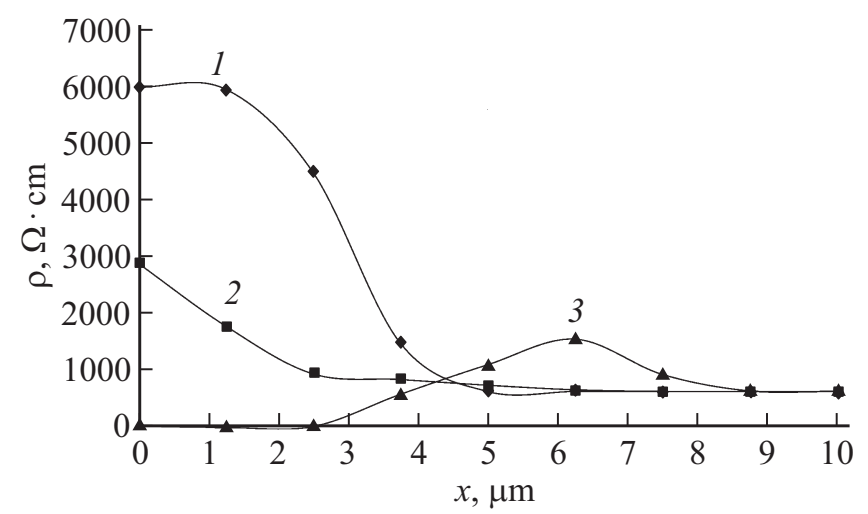

Рис. 2. Профили по координате $x$ удельного сопротивления $\rho$ кристаллического кремния после облучения протонами с $E=100+200+300$ кэВ, $D=2 \cdot 10^{16} \mathrm{~cm}^{-2}$ и отжига: 1 непосредственно после облучения; 2 - после облучения и отжига при $T=200^{\circ} \mathrm{C}, 2$ ч; 3 - после облучения и отжига при $T=300^{\circ} \mathrm{C}, 2$ ч.

уменьшается до величины значительно ниже исходного уровня (в 50-100 раз). Более того, при таком отжиге на глубине от 3 до 8 мкм формируется заглубленный слой с повышенным удельным сопротивлением, что заметно превышает пробег протонов (рис. 2, кривая 3). Этот факт можно объяснить следующим образом. При температуре $200^{\circ} \mathrm{C}$ начинают отжигаться поверхностные дефекты, компенсирующие проводимость. При температуре $300^{\circ} \mathrm{C}$ они отжигаются в наибольшей степени. При этом вблизи поверхности начинают образовываться „мелкие“ водородные центры, обладающие донорными свойствами. Вследствие этого поверхностное удельное сопротивление падает по сравнению с исходным значением (рис. 2, кривая 3). В глубине кристалла за границей пробега протонов формируется слой, насыщенный микродефектами (см. табл. 1), „перекаченными“ от поверхности (эффект дальнодействия, наблюдаемый в работе [3]). Эти „перекаченные“ дефекты обладают компенсирующими свойствами, как и дефекты, инициированные облучением (рис. 2, кривая 1). Именно поэтому дефектный заглубленный слой имеет повышенное удельное сопротивление по сравнению с исходным кристаллом.

Наибольшее удельное сопротивление заглубленный слой приобретает в результате отжига при $T=300^{\circ} \mathrm{C}$ (рис. 2, кривая 3). При более высоких температурах компенсирующие дефекты этого слоя, а также „донорные“ дефекты поверхностного слоя постепенно отжигаются, что и приводит к росту темнового тока ФЧП (рис. $1, a)$ и ОК (рис. $1, b)$.

На рис. 3 представлены ВАХ изучаемых структур. Отметим, что допустимое значение темнового тока $I_{d}$ не должно превышать 2.5 мкА при $U_{\mathrm{rev}}=200 \mathrm{~B}$.

Исходя из изложенного, можно предложить следующий механизм изменения величины обратного тока pin-ФД в результате облучения их периферии протонами и отжига. Обратная ветвь ВАХ исходной структуры

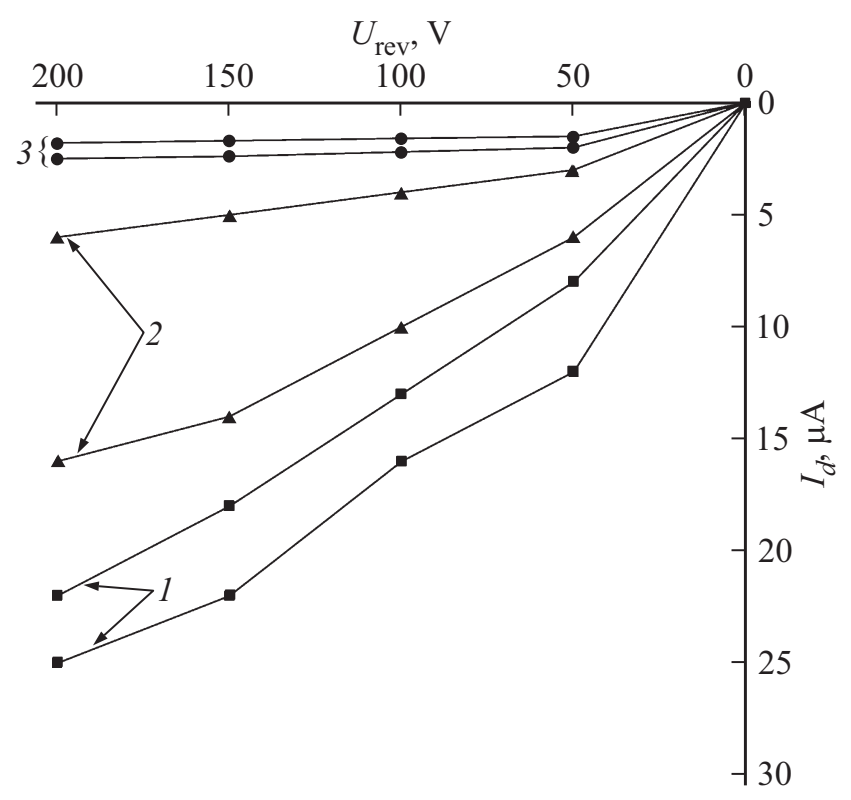

Рис. 3. Изменение ВАХ pin-ФД после протонного облучения и отжига: 1 - семейство исходных ВАХ; 2 - семейство ВАХ после облучения протонами с $E=100+200+300$ кэВ, $D=2 \cdot 10^{16} \mathrm{~cm}^{-2} ; 3-$ семейство ВАХ после облучения протонами и отжига при $T=300^{\circ} \mathrm{C}, 2$ ч. 
(рис. 3, семейство кривых 1) определяется поверхностной генерацией. Снижение величины темнового тока непосредственно после облучения (рис. 3, семейство кривых 2) объясняется формированием поверхностного компенсированного дефектного слоя, приводящим к уменьшению влияния поверхностной генерации, а ВАХ становится определяемой в основном токами генерации в ОПЗ металлургической границы $p-n$-перехода, причем в большей мере при включении ОК, которое „оттягивает“ на себя часть носителей заряда, генерированных на поверхности. Отжиг при температуре $300^{\circ} \mathrm{C}$ приводит к формированию тонкого ( 3 мкм $)$ поверхностного слоя с пониженным и, по-видимому, оптимальным сопротивлением (этот слой изолирован от объема заглубленным слоем с повышенным удельным сопротивлением), по которому часть тока ФЧП перетекает в ОК. В результате темновой ток становится еще меньше, а ВАХ ФЧП в еще большей мере определяется генерацией в ОПЗ металлургической границы $p-n$-перехода (рис. 3, семейство кривых 3).

После отжига при температурах выше $300^{\circ} \mathrm{C}$ дефекты, определяющие существование поверхностного и заглубленного слоев, исчезают и темновой ток ФЧП и ОК возвращаются к исходному (до облучения) состоянию (рис. $1, a, b)$, определяемому поверхностной генерацией и инверсионным каналом.

\section{4. Заключение}

С помощью методов ТРД и ПЭМ в работе было оценено общее состояние нарушенного слоя при имплантации кристаллов кремния протонами с последовательным ступенчатым увеличением энергии от 100 до 300 кэВ с шагом 100 кэВ, общей дозой $2 \cdot 10^{16} \mathrm{~cm}^{-2}$, на разных этапах термообработки в широком интервале температур. В сочетании с измерениями электрофизических характеристик отработан конкретный технологический режим для коррекции характеристик pin-фотодиодов с целью увеличения выхода годных приборов.

Экспериментально показано, что для снижения темновых токов кремниевых pin-фотодиодов с ОК на основе диффузионных планарных $n^{+}-p$-переходов глубиной $\sim 3$ мкм следует проводить имплантацию ионов водорода с энергией $100+200+300$ кэВ и дозой $2 \cdot 10^{16} \mathrm{~cm}^{-2}$ локально в области между основными $n^{+}-p$-переходами и ОК с захватом $n^{+}$-областей. Также необходим постимплантационный отжиг в вакууме при температуре $300^{\circ} \mathrm{C}$ в течение 2 ч. Установлено, что протонное облучение периферии планарных $p^{+}-n$-переходов в указанном режиме уменьшает их темновой ток благодаря формированию поверхностного дефектного слоя с компенсированной проводимостью. Наличие такого слоя уменьшает негативное влияние поверхности на темновые токи. Отжиг облученных структур при температуре $300^{\circ} \mathrm{C}$ формирует поверхностный слой толщиной $\sim 3$ мкм с оптимальным для перетекания части тока ФЧП в ОК сопротив- лением. Этот слой отделен от объема кристалла заглубленным слоем толщиной 3-8 мкм с компенсированной проводимостью, образующимся только при указанной температуре. Таким образом, экспериментально определенный режим обработки периферии pin-ФД на основе высокоомного кремния позволил улучшить параметры готовых фотодиодных структур и значительно увеличить выход годных приборов.

Отметим, однако, что для каждого случая конкретного практического применения режимы ионной имплантации и отжига должны подбираться индивидуально.

\section{Благодарности}

Авторы статьи выражают благодарность д.ф.-м.н. Л.М. Сорокину, Физико-технический институт им. А.Ф. Иоффе Российской академии наук, за помощь в проведении электронномикроскопических исследований и к.Т.Н. К.В. Сорокину, Московская государственная академия тонкой химической технологии имени М.В. Ломоносова, за помощь в получении электрофизических характеристик исследуемых образцов.

\section{Финансирование работы}

Работа выполнена при поддержке Министерства науки и высшего образования в рамках выполнения работ по Государственному заданию ФНИЦ „Кристаллография и фотоника“ РАН.

\section{Конфликт интересов}

Авторы заявляют, что у них нет конфликта интересов.

\section{Список литературы}

[1] И.П. Безродных, А.П. Тютнев, В.Т. Семенов. Радиационные эфбекты в космосе. Влияние ионизирующего излучения на изделия электронной техники (М., АО „Корпорация ВНИИЭМ““, 2017) ч. 3.

[2] M. Bruel. Electron. Lett., 31 (14), 1201 (1995).

[3] В.В. Козловский. Модифицирование полупроводников пучками протонов (СПб., Наука, 2003).

[4] В. Губарев, А. Семенов, А. Сурма, В. Столбунов. Силовая электроника, 5, 108 (2011).

[5] S. Kirnstötter, M. Faccinelli, M. Jelinek, W. Schustereder, J.G. Laven, H.J. Schulze, P. Hadley. Sol. St. Phenomena, 205-206, 311 (2014).

[6] И.Г. Дьячкова, Е.Г. Новоселова, И.С. Смирнов. Тр. ХХV Межсдунар. конф. Радиационная физика твердого тела“ (Севастополь, 2015) с. 539.

[7] H. Schmalzwasser, A. Richter. In: Wissenschaftliche Zeitschrift der Friedrich-Schiller-Universitaet Jena (Jena, Friedrich-Schiller-Universitaet, 1986) 35 (4), p. 505.

[8] P. Wendland. Optical Spectra, 7 (10), 33 (1973).

[9] С. Зи. Физика полупроводниковых приборов (М., Энергия, 1984).

[10] Физика поверхности полупроводников. Сб. статей, пер. с англ. под ред. Г.Е. Пикуса (М., Изд. иностр. лит., 1959). 
[11] P. Wendland. Electro-Optical Systems Design, 8, 48 (1970).

[12] Б.М. Вул. Физика диэлектриков и полупроводников (М., Наука, 1988).

[13] П.А. Александров, Е.К. Баранова, И.В. Баранова, В.В. Бударагин, В.Л. Литвинов. Тр. ХII Межсдунар. совеш. ,Paдиационная физика твердого тела“ (Севастополь, 2002) c. 149.

[14] А.Ф. Буренков. Таблищы параметров пространственного распределения ионно-имплантированных примесей (Минск, БГУ, 1980).

[15] В.Е. Асадчиков, И.Г. Дьячкова, Д.А. Золотов, Ф.Н. Чуховский, Л.М. Сорокин. ФТТ, 61 (8), 1437 (2019).

[16] В.Е. Асадчиков, И.Г. Дьячкова, Д.А. Золотов, Ф.Н. Чуховский, Л.М. Сорокин. ФТТ, 61 (10), 1754 (2019).

[17] В.Е. Асадчиков, И.Г. Дьячкова, Д.А. Золотов, Ю.С. Кривоносов, В.Т. Бублик, А.И. Шихов. ИВУЗ. МЭТ, 22 (1), 11 (2019).

Редактор Л.В. Шаронова

\section{Correction of silicon photodiodes characteristics by applying ion implantation}

V.E. Asadchikov' ${ }^{1}$ I.G. Dyachkova ${ }^{1}$, D.A. Zolotov' ${ }^{1}$, F.N. Chukhovskii ${ }^{1}$, E.V. Nikitina ${ }^{2}$

${ }^{1}$ Federal Scientific Research Centre "Crystallography and Photonics", Russian Academy of Sciences, 119333 Moscow, Russia

${ }^{2}$ St. Petersburg National Research Academic University (Alferov University), Russian Academy of Sciences, 194021 St. Petersburg, Russia

Abstract The paper considers the data of measurement of silicon pin-photodiodes electrophysical parameters after implantation of defect-forming ions and subsequent heat treatment, which open a new way to reduce the dark current and increase the output of suitable devices. The data of electrophysical measurements are compared with the results of structural studies. The efficiency of proton irradiation of the periphery of $n^{+}-p$ transitions to protect the surface of pin-photodiodes based on high resistance silicon was experimentally established. Optimal conditions - modes of proton irradiation and subsequent thermal annealing (energy $E=100+200+300 \mathrm{Kev}$, dose $D=2 \cdot 10^{16} \mathrm{~cm}^{-2}$, temperature $T=300^{\circ} \mathrm{C}$, time $t=2 \mathrm{~h}$ ), at which the formation of a surface layer with optimal characteristics for achieving minimum dark currents of photosensitive sites and the guard ring occurs are determined. The application of these modes to serial pin photodiodes with a depth of $n^{+}-p$ transitions $\sim 3 \mu \mathrm{m}$ allowed to reduce the dark current by an order of magnitude and increase the output of suitable devices. 